\title{
One-Pot Synthesis and AFM Imaging of a Triangular Aramide Macrocycle
}

\author{
Christof Storz, ${ }^{\dagger}$ Michael Badoux, ${ }^{\dagger}$ Christopher M. Hauke, ${ }^{\ddagger}, \S$ Tomáš Šolomek, $^{\dagger, \|}$ Angelika Kühnle, ${ }^{\ddagger}$ \\ Thomas Bally, ${ }^{\dagger}$ and Andreas F. M. Kilbinger* ${ }^{\dagger}$ \\ ${ }^{\dagger}$ Department of Chemistry, University of Fribourg, Chemin du Musée 9, CH-1700 Fribourg, Switzerland \\ ${ }^{\ddagger}$ Institut für Physikalische Chemie, Johannes Gutenberg Universität Mainz, Duesbergweg 10-14, D-55099 Mainz, Germany \\ ${ }^{\S}$ Graduate School of Excellence Materials Science in Mainz, Staudinger Weg 9, D-55128 Mainz, Germany \\ "RECETOX and Department of Chemistry, Faculty of Science, Masaryk University, Kamenice 5, 625 00, Brno, Czech Republic
}

Supporting Information

ABSTRACT: Macrocyclizations in exceptionally good yields were observed during the self-condensation of $\mathrm{N}$ benzylated phenyl $p$-aminobenzoates in the presence of LiHMDS to yield three-membered cyclic aramides that adopt a triangular shape. An ortho-alkyloxy side chain on the $N$-benzyl protecting group is necessary for the macrocyclization to occur. Linear polymers are formed exclusively in the absence of this Li-chelating group. A model that explains the lack of formation of other cyclic congeners and the demand for an $\mathrm{N}$-(o-alkoxybenzyl) protecting group is provided on the basis of DFT calculations. High-resolution AFM imaging of the prepared molecular triangles on a calcite(10.4) surface shows individual molecules arranged in groups of four due to strong surface templating effects and hydrogen bonding between the molecular triangles.

hape-persistent macrocycles ${ }^{1-4}$ are of special interest due $\checkmark$ to their rigid backbone, which often leads to selfaggregation into columnar stacks, and that can be eventually used for transport and separation processes ${ }^{5,6}$ or as rigid scaffolds with well-defined cavities for catalytic or biomimetic applications. ${ }^{7,8}$

The preparation of macrocycles presents a major challenge and has thus been studied intensively. A typical approach to a macrocycle is an intramolecular end to end macrocyclization of a linear $\alpha, \omega$-difunctionalized precursor which is synthesized in a stepwise manner. Such a synthesis is often obstructed by formation of undesired side products, low reaction yields, and the need for high-dilution conditions. ${ }^{9,10}$ Therefore, highly efficient preparations of macrocycles have become the subject of considerable importance. Several strategies have been reported to improve the efficiency of macrocyclizations such as cyclooligomerization, ${ }^{4}$ intermolecular coupling between two or more oligomeric fragments, ${ }^{4}$ or templated cyclizations ${ }^{11,12}$ and strategies based on dynamic covalent chemistry. ${ }^{13-15}$ Among the various methods to build a macrocycle, the one-pot approach is of particular interest. However, most of the onestep cyclizations described so far lead to rather low yields due to the entropically disfavored nature of the cyclization and the ensuing extensive separation and purification steps.
Formation of cyclic aramides. During our work ${ }^{16,17}$ on polycondensation of phenyl $p$-aminobenzoates 1 substituted with the acid labile $N$-2,4-dimethoxybenzyl and the more bulky $N$-2,4-bis((2-ethylhexyl)oxy)benzyl group we observed, besides the anticipated formation of linear polymers, an unexpected formation of cyclic tri( $p$-benzamide)s 2 . As shown in Scheme 1,

Scheme 1. Conformation-Directed Macrocyclization (n.o. = not observed)

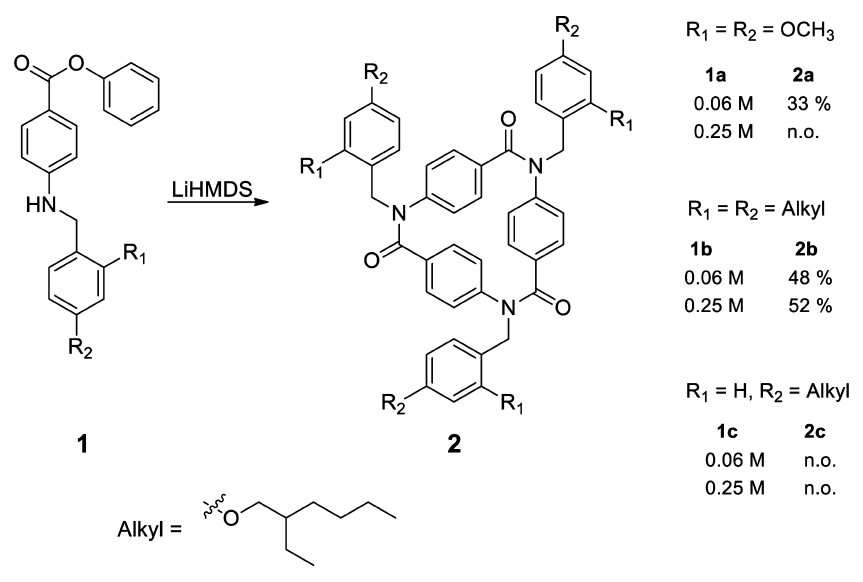

self-condensation of a $0.06 \mathrm{M}$ solution of monomers 1 with 1.5 equiv of LiHMDS ( $1 \mathrm{M}$ solution in THF) afforded the corresponding cyclic trimers $\mathbf{2}$ and a linear polymer. The formation of 2 was confirmed by high-resolution MALDI FTICR mass spectrometry (Figure SI16,17) and NMR spectroscopy (Figure SI7,8). The isolated yield of 2 (33\% and $48 \%$ for $\mathbf{2 a}$ and $\mathbf{2} \mathbf{b}$, respectively) was higher when the more bulky $N$ protecting group was used. At increasing monomer concentrations, the formation of $2 \mathrm{a}$ diminished until a linear polymer was the only product, whereas the yield of $\mathbf{2} \mathbf{b}$ was hardly affected. The higher steric bulk of the 2-ethylhexyl group presumably hinders the nucleophilic attack of 1 on the openring form of the trimer and, therefore, prevents the polymer chain growth even at a relatively high concentration of monomer 1.

Received: July 2, 2014

Published: September 1, 2014 
The formation of $\mathbf{2}$ was rather surprising because it has been previously shown that the macrocyclization of methyl $\mathrm{N}-(2,4-$ dimethoxybenzyl)-4-aminobenzoate in the presence of LiHMDS to form 2 was unsuccessful, most probably because of the deactivation of the methyl ester by the aminyl anion. ${ }^{18} \mathrm{~A}$ more reactive ester group (phenyl ester) is apparently needed for the self-condensation of the monomer to occur. ${ }^{19}$ In addition, self-condensation of extended methyl aminobenzoates (based on trans-stilbene and diphenylacetylene) that cannot be deactivated by the aminyl anion has already been reported. ${ }^{20}$

When the monomer 1c, which bears only a $p$-alkoxy substituted $N$-benzyl protecting group, was exposed to the same reaction conditions described above (Scheme 1), only a linear polymer resulted at both concentrations, as evidenced by gel permeation chromatography (Table SI1).

There are several examples of conformation $-{ }^{20-29}$ and $\mathrm{H}-$ bonding $-{ }^{30-37}$ directed macrocyclizations based on amide bond formation. In previous investigations of cyclic para-linked oligoaramides the group of Azumaya et al. described the synthesis of $N$-methylated cyclic trimers, ${ }^{22,26}$ similar to those that we observe in our current work, with dehydration agents. Yokozawa et al. showed the formation of $\mathrm{N}$-alkylated cyclic hexamers from dimers in the presence of a strong base under high-dilution conditions. ${ }^{28}$

The preferential formation of trimers. The formation of the three-membered macrocyclic aramides, which can easily be shown to have more strain energy than their larger congener 4 (Figure 1, Table SI2), can be explained by biased

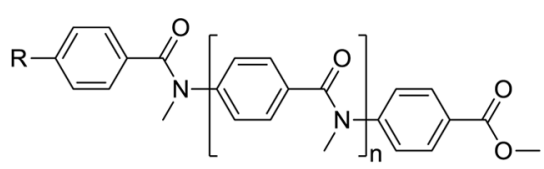

$$
\begin{array}{ll}
\text { 3, } \mathrm{n}=1: \mathrm{R}=\mathrm{NHCH}_{3} & \text { 3', } \mathrm{n}=1: \mathrm{R}=\stackrel{\ominus}{\mathrm{NCH}} \mathrm{NCH}_{3} \\
\text { 4, } \mathrm{n}=\text { 2: } \mathrm{R}=\mathrm{NHCH}_{3} & \mathbf{4}^{-}, \mathrm{n}=2: \mathrm{R}=\stackrel{\ominus}{\mathrm{NCH}} \mathrm{NCH}_{3}
\end{array}
$$

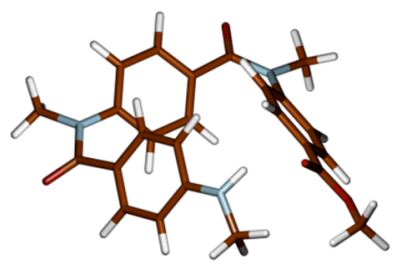

3

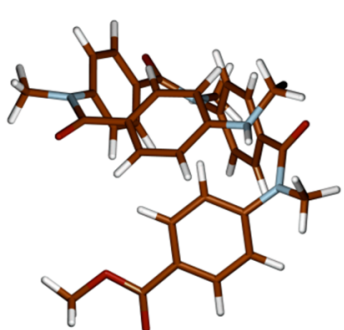

4
Figure 1. Structures of the models used in the conformational search (top) and the corresponding lowest-energy conformers of $\mathbf{3}$ and $\mathbf{4}$ (bottom). Other conformers can be found in the SI.

conformations that the open-ring forms of $\mathbf{2}$ adopt in the solution. We performed calculations to support this notion previously reported by groups of Yokozawa ${ }^{39}$ and Wilson. ${ }^{29} \mathrm{~A}$ library of conformers of model open-ring trimer 3, tetramer 4 (Figure 1), and their conjugate bases was generated by a conformational search algorithm followed by a subsequent optimization using M06-2X density functional (details in SI). The final computed energies were used to calculate the Boltzmann distribution of the conformers in a THF solution. The preferred cis conformation of $\mathrm{N}$-substituted aromatic amides $^{38}$ confines $\mathbf{3}$ or $\mathbf{4}$ to preferentially adopt all-cis conformations. A helical conformation is, therefore, strongly preferred in tetramer 4 and presumably in longer congeners, ${ }^{39}$ while the four lowest-energy conformations of 3 or $3^{-}$ represent potential energy minima that directly lead to the corresponding macrocycles (Tables SI3-SI6; Figures SI22 and SI23). Thus, the probability of longer oligomers to unfold the "helix" to adopt conformations that lead to macrocyclization is very low compared to that of trimers, for which the macrocyclization occurs also at relatively high monomer concentration in spite of the penalizing strain energy.

Our calculations show that the $\mathrm{Li}^{+}$ion is indeed strongly coordinated to the deprotonated nitrogen atom in $\mathbf{1}$ (Table SI7), and it will thus serve as an additional templating element like the $\mathrm{H}$-bonds in $\mathbf{3}$, and it will also affect the transition states to macrocyclization.

The role of the $\mathrm{N}$-(o-alkoxybenzyl) protecting group. These transition states were located first for $3^{-}$in the absence of $\mathrm{Li}^{+}$. We found four transition states that lead to tetrahedral intermediates (see 6 in Scheme 2), from which the ester alkoxy group departure provides the final macrocycle.

Scheme 2. A Model Macrocyclization Reaction

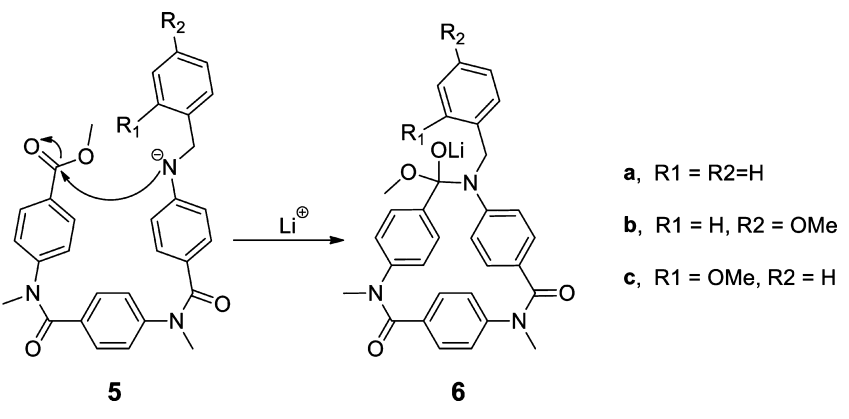

These transition states differ in relative orientation of the $N$ $\mathrm{Me}$ and the ester methoxy groups. Coordination of a $\mathrm{Li}^{+}$ stabilizes the open-ring forms and increases the reaction barrier considerably (from 5 to 11 to $>16 \mathrm{kcal} \mathrm{mol}^{-1}$ ) for all but one of the four transition states, which remained nearly unaffected (entry 1 in Table 1, details in SI). This was then modified to

Table 1. Energies of the Macrocyclization Transition States

$\begin{array}{ccc}\text { entry } & \text { compound } & \left.\Delta E(0 \mathrm{~K}, \mathrm{kcal} \mathrm{mol})^{-1}\right)^{a} \\ 1 & 3^{-} \cdots \mathrm{Li}^{+} & 10.0 \\ 2 & 5 \mathrm{a} & 12.4 \\ 3 & 5 \mathrm{~b} & 11.6 \\ 4 & 5 \mathrm{c} & 9.0\end{array}$

${ }^{a} \mathrm{M} 06-2 \mathrm{X} / 6-311+\mathrm{G}(2 \mathrm{~d}, \mathrm{p}) / \mathrm{PCM}$ energies on M06-2X/6-31G(d)/ PCM optimized geometries with nonscaled ZPVE corrections included; details in SI.

bear a substituted $N$-benzyl protecting group $(5 \mathbf{a}-\mathbf{c}$ in Scheme 2 ). The barriers found with the reoptimized transition states are summarized in Table 1, and the structure of the lowest-energy transition state is depicted in Figure 2. The presence of an $o$ alkoxy group has further lowered the energy of the transition state to macrocyclization, while it has increased for all other derivatives considered. The structure of the transition state in Figure 2 suggests that an $\mathrm{N}$-(o-alkoxybenzyl) protecting group with additional steric bulk may additionally help to prevent the chain growth process by blocking the incoming nucleophilic monomer in agreement with our experimental observation (see Scheme 1). 

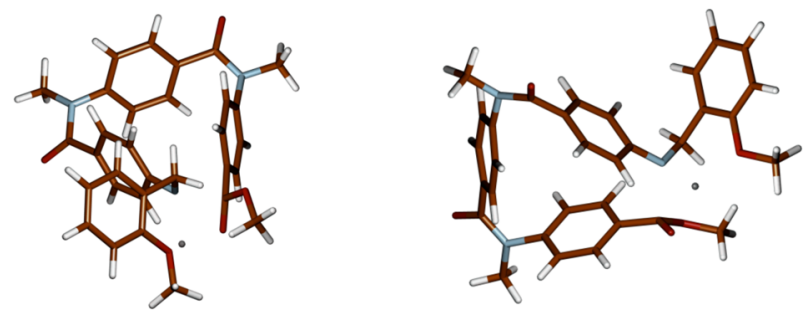

Figure 2. Macrocyclization transition state for $\mathbf{5 c}$ with a $\mathrm{Li}^{+}$counterion (gray dot) coordinated in between the amino nitrogen and the ester carbonyl oxygen atoms; side-view (left) and bottom-view (right).

Deprotection of $\mathrm{N}$-(o-alkoxybenzyl) protecting groups. An acid-promoted deprotection of the two cyclic trimers $\mathbf{2 a}, \mathbf{b}$ in trifluoroacetic acid in the presence of triisopropylsilane and heating at $65{ }^{\circ} \mathrm{C}$ for $18 \mathrm{~h}$ (Scheme 3) resulted in the cyclic

Scheme 3. Deprotection of Cyclic Trimers 2

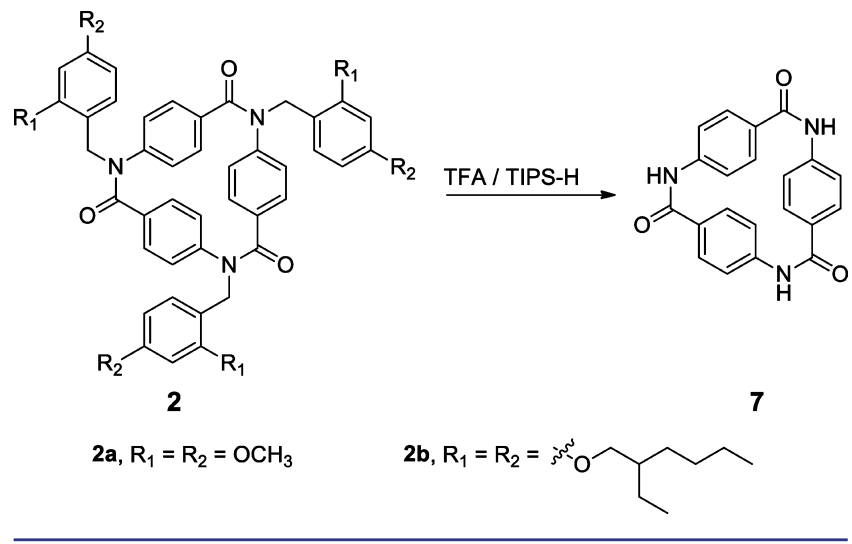

tri( $p$-benzamide $) 7$ that has previously been reported by the group of Wilson in a 10 step synthesis with an overall yield of $8 \% .{ }^{24}$ With our improved one-step macrocyclization approach, 7 is now accessible in three straightforward steps with an overall yield of $43 \%$.

The AFM study of 7 on a calcite surface. The crystal structure of 7 features three cis-amides positioned within the same plane separated by $120^{\circ}$ angles that are connected via $\mathrm{H}$-bonding in exclusively two dimensions. ${ }^{24}$ Such a structural feature could lead to highly ordered H-bonded two-dimensional networks. A sample of 7 was therefore sublimed onto a calcite(10.4) surface and investigated by noncontact atomic force microscopy (NCAFM) in ultrahigh vacuum. Due to its comparatively high surface energy, calcite has been proven to be a viable candidate for molecular self-assembly on an insulating surface. ${ }^{40}$ Indeed, NC-AFM measurements reveal the formation of islands that form stable wetting layers with a highly ordered inner structure (Figure 3).

Figure 4a shows a typical high-resolution image of the selfassembled structure. The apparent height of the islands of 0.4$0.5 \mathrm{~nm}$ and the spot size are in good agreement with the molecular dimensions of 7 . We hence assign each spot in the image to a single molecule. The spots are arranged in units of four, as indicated by the gray and black circles. These units form molecular rows running from the upper left to the lower right corner in the image. A possible model of the molecular orientation is given in Figure $4 b$, largely matching the molecule's crystal structure. ${ }^{24}$ The rows' repeat distance of $(2.0 \pm 0.1) \mathrm{nm}$ along the substrate $[01.0]$ direction is enlarged
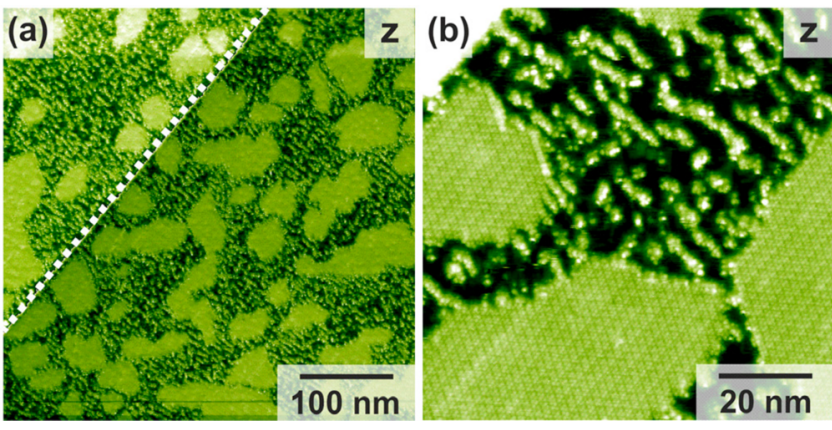

Figure 3. (a,b) NC-AFM topography images of the self-assembled structures of 7 after the deposition on calcite(10.4). Note that the calcite step edge, marked by the dashed line in (a), does not serve as nucleation center. (b) Magnification of the structures shown in (a). Already at this scale, the highly ordered inner structure is visible.

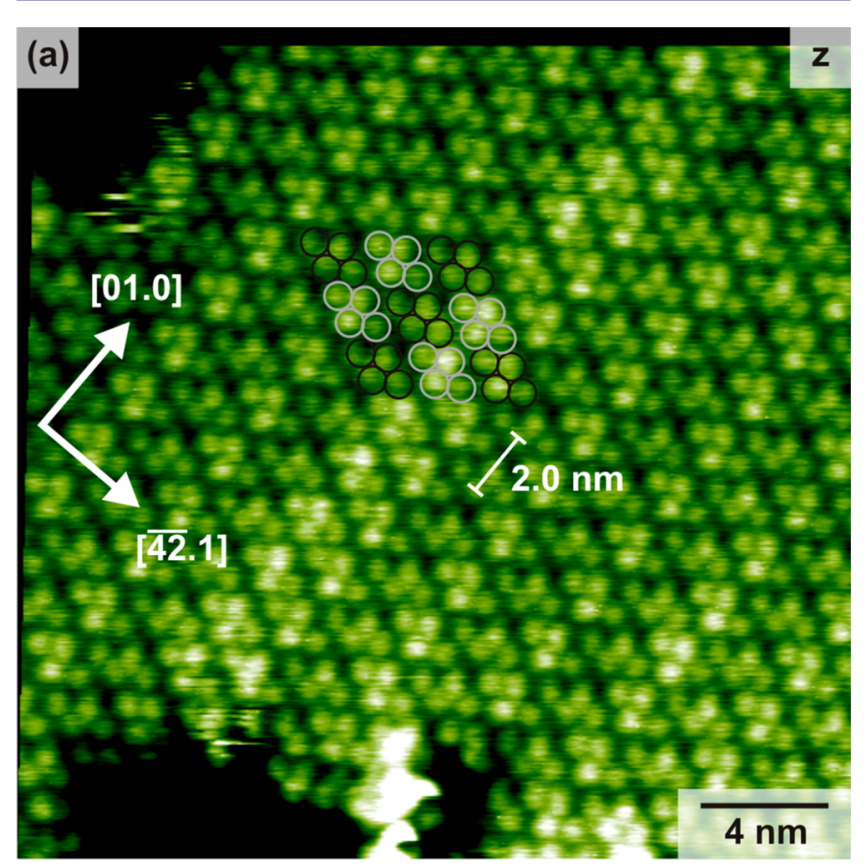

(b)

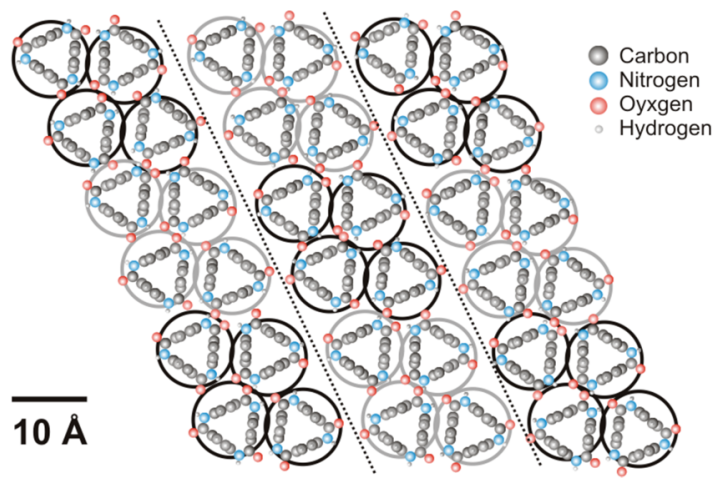

Figure 4. (a) High-resolution NC-AFM topography image of a selfassembled wetting layer of cyclic tri(p-benzamide) 7 on the calcite(10.4) surface. The main crystal directions are given by the arrows. (b) Possible model for the molecular orientation.

by $\sim 13 \%$ with respect to the crystal structure but exactly matches four times the calcite repeat distance of $0.5 \mathrm{~nm}$ along this direction. The deviation from the crystal structure is thus most likely caused by the substrate's strong templating effect, 
causing the self-assembled structures to adapt to the surface structure and orientation. This templating effect has been observed for a considerable amount of organic molecules on the calcite(10.4) surface. $^{41}$

In conclusion, we have demonstrated that cyclic tri $(p$ benzamide)s 2 can be obtained via one-step macrocyclization in exceptionally high yields using chelating $N$-protecting groups in combination with LiHMDS. Furthermore, a model for the macrocyclization is proposed and supported by DFT calculations. The macrocycle 2 can be easily deprotected to yield 7 that represents a shape-persistent "molecular triangle". High-resolution AFM revealed its highly ordered two-dimensional orientation on calcite surfaces. Such ordered arrays of macrocycles might prove useful for the encapsulation of guest molecules or suitably sized cations with well-defined spatial separation.

\section{ASSOCIATED CONTENT}

\section{S Supporting Information}

Experimental procedures and NMR, GPC, ESI-MS, MALDI FT-ICR MS, and AFM data. This material is available free of charge via the Internet at http://pubs.acs.org.

\section{AUTHOR INFORMATION}

\section{Corresponding Author}

andreas.kilbinger@unifr.ch

\section{Notes}

The authors declare no competing financial interest.

\section{ACKNOWLEDGMENTS}

The authors thank the Deutsche Forschungsgemeinschaft (DFG) and the Swiss National Science Foundation (SNF) for funding. T.S. acknowledges the support from the Czech Ministry of Education (LO1214).

\section{REFERENCES}

(1) Grave, C.; Schluter, A. D. Eur. J. Org. Chem. 2002, 3075.

(2) Zhao, D. H.; Moore, J. S. Chem. Commun. 2003, 807.

(3) MacLachlan, M. J. Pure. Appl. Chem. 2006, 78, 873.

(4) Zhang, W.; Moore, J. S. Angew. Chem., Int. Ed. 2006, 45, 4416.

(5) Pasini, D.; Ricci, M. Curr. Org. Synth. 2007, 4, 59.

(6) Bong, D. T.; Clark, T. D.; Granja, J. R.; Ghadiri, M. R. Angew. Chem., Int. Ed. 2001, 40, 988.

(7) Rebek, J. Science 1987, 235, 1478.

(8) Martell, A. E.; Perutka, J.; Kong, D. Coord. Chem. Rev. 2001, 216, 55.

(9) Knops, P.; Sendhoff, N.; Mekelburger, H. B.; Vogtle, F. Top. Curr. Chem. 1992, 161, 3.

(10) Rossa, L.; Vogtle, F. Top. Curr. Chem. 1983, 113, 1.

(11) Mccallien, D. W. J.; Sanders, J. K. M. J. Am. Chem. Soc. 1995, 117,6611 .

(12) Anderson, H. L.; Sanders, J. K. M. Angew. Chem., Int. Ed. 1990, 29, 1400.

(13) Rowan, S. J.; Cantrill, S. J.; Cousins, G. R. L.; Sanders, J. K. M.; Stoddart, J. F. Angew. Chem., Int. Ed. 2002, 41, 898.

(14) Furlan, R. L. E.; Otto, S.; Sanders, J. K. M. Proc. Natl. Acad. Sci. U.S.A. 2002, 99, 4801.

(15) Otto, S.; Furlan, R. L. E.; Sanders, J. K. M. J. Am. Chem. Soc. 2000, 122, 12063.

(16) Storz, C.; Schulze, M.; Kilbinger, A. F. M. Macromol. Rapid Commun. 2011, 32, 238.

(17) Schulze, M.; Michen, B.; Fink, A.; Kilbinger, A. F. M. Macromolecules 2013, 46, 5520.

(18) Campbell, F.; Wilson, A. J. Tetrahedron Lett. 2009, 50, 2236.
(19) Yokozawa, T.; Sugi, R.; Asai, T.; Yokoyama, A. Chem. Lett. 2004, 33, 272.

(20) Yokoyama, A.; Maruyama, T.; Tagami, K.; Masu, H.; Katagiri, K.; Azumaya, I.; Yokozawa, T. Org. Lett. 2008, 10, 3207.

(21) Blankenstein, J.; Zhu, J. P. Eur. J. Org. Chem. 2005, 1949.

(22) Azumaya, I.; Okamoto, T.; Imabeppu, F.; Takayanagi, H. Heterocycles 2003, 60, 1419.

(23) Katagiri, K.; Tohaya, T.; Masu, H.; Tominaga, M.; Azumaya, I. . J. Org. Chem. 2009, 74, 2804.

(24) Campbell, F.; Kilner, C. A.; Wilson, A. J. Tetrahedron Lett. 2010, $51,1361$.

(25) Ohishi, T.; Suzuki, T.; Niiyama, T.; Mikami, K.; Yokoyama, A.; Katagiri, K.; Azumaya, I.; Yokozawa, T. Tetrahedron Lett. 2011, 52, 7067.

(26) Katagiri, K.; Ikeda, T.; Muranaka, A.; Uchiyama, M.; Tominaga, M.; Azumaya, I. Tetrahedron: Asymmetry 2009, 20, 2646.

(27) Azumaya, I.; Kagechika, H.; Yamaguchi, K.; Shudo, K. Tetrahedron Lett. 1996, 37, 5003.

(28) Yokoyama, A.; Shimizu, Y.; Yokozawa, T. Chem. Lett. 2005, 34, 1128.

(29) Campbell, F.; Plante, J.; Carruthers, C.; Hardie, M. J.; Prior, T. J.; Wilson, A. J. Chem. Commun. 2007, 2240.

(30) Carver, F. J.; Hunter, C. A.; Shannon, R. J. J. Chem. Soc. Chem. Comm. 1994, 1277.

(31) Xing, L. Y.; Ziener, U.; Sutherland, T. C.; Cuccia, L. A. Chem. Commun. 2005, 5751.

(32) Du, Z. Y.; Ren, C. L.; Ye, R. J.; Shen, J.; Maurizot, V.; Lu, Y. J.; Wang, J.; Zeng, H. Q. Chem. Commun. 2011, 47, 12488.

(33) Qin, B.; Ong, W. Q.; Ye, R. J.; Du, Z. Y.; Chen, X. Y.; Yan, Y.; Zhang, K.; Su, H. B.; Zeng, H. Q. Chem. Commun. 2011, 47, 5419.

(34) Jiang, H.; Leger, J. M.; Guionneau, P.; Huc, I. Org. Lett. 2004, 6, 2985.

(35) Yuan, L. H.; Feng, W.; Yamato, K.; Sanford, A. R.; Xu, D. G.; Guo, H.; Gong, B. J. Am. Chem. Soc. 2004, 126, 11120.

(36) Ferguson, J. S.; Yamato, K.; Liu, R.; He, L.; Zeng, X. C.; Gong, B. Angew. Chem., Int. Ed. 2009, 48, 3150.

(37) Feng, W.; Yamato, K.; Yang, L. Q.; Ferguson, J. S.; Zhong, L. J.; Zou, S. L.; Yuan, L. H.; Zeng, X. C.; Gong, B. J. Am. Chem. Soc. 2009, 131, 2629.

(38) Itai, A.; Toriumi, Y.; Tomioka, N.; Kagechika, H.; Azumaya, I.; Shudo, K. Tetrahedron Lett. 1989, 30, 6177.

(39) Tanatani, A.; Yokoyama, A.; Azumaya, I.; Takakura, Y.; Mitsui, C.; Shiro, M.; Uchiyama, M.; Muranaka, A.; Kobayashi, N.; Yokozawa, T. J. Am. Chem. Soc. 2005, 127, 8553.

(40) Rahe, P.; Lindner, R.; Kittelmann, M.; Nimmrich, M.; Kühnle, A. Phys. Chem. Chem. Phys. 2012, 14, 6544.

(41) Rahe, P.; Kittelmann, M.; Neff, J. L.; Nimmrich, M.; Reichling, M.; Maas, P.; Kühnle, A. Adv. Mater. 2013, 25, 3948. 